\title{
Measurement of Light Luminance and Temperature Monitoring for Real Time Energy Saving Applications Using Arduino Uno Atmega328
}

\author{
Mangesh V. Kulkarni, Suraj R. Kulkarni, Chetan A. Harti, \\ Babroo K. Chavan and Vyas R. Murnal
}

\begin{abstract}
Energy conservation is currently being discussed globally across all platforms. However, the technical measures taken are not sufficient to solve the problem of energy crisis. In real time applications like street light control and maintenance, automation resulting in saving of energy is very important and critical. The paper presents an effective solution for automatic street light control by measuring the luminance of light in order to reduce the power wastage that happens during the day time. When light with different luminance is incident on a Light dependent resistor (LDR), its resistance varies according to the luminance of the light falling on it. Considering the LDR as part of a Signal conditioning circuit, we have obtained the output voltage that depends on the change in the resistance of the LDR. Hence, by measuring the output voltage, the luminance of the incident light on the surface is obtained. Finally, a relationship is established between luminance on the surface of the LDR and the distance of the light source. The paper also aims at designing an efficient multipurpose thermistor based temperature monitoring system that helps in the automation for real time applications.
\end{abstract}

Keywords--- Luminance, LUX, Arduino, Temperature Monitoring.

\section{INTRODUCTION}

$\mathrm{I}_{\mathrm{o}}^{\mathrm{N}}$ NCREASING Energy crisis and possible solutions to overcome it is currently being discussed worldwide. Based upon the surveys done on Energy management [1], it is clear that the usage of renewable resources has to be encouraged. At the same time, effective methods for the usage of nonrenewable resources need to be developed. In addition, simple and effective automation techniques can help significantly in the reduction of power wastage in real time applications. This paper aims at the design, implementation and simulation of a simple but effective embedded system for energy saving in street lights. The present system is such that, the street lights

Mangesh V. Kulkarni, Student, UG, $3^{\text {rd }}$ Year ECE, SDMCET, E-mail: mangesh.kulkarni707@gmail.com

Suraj R. Kulkarni, Studens, UG, $3^{\text {rd }}$ Year ECE, SDMCET, E-mail: surajrkdwd@gmail.com

Chetan A. Harti, Student, UG, $3^{\text {rd }}$ Year ECE, SDMCET, E-mail: chetanharti@gmail.com

Babroo K. Chavan, Students, UG, $3^{\text {rd }}$ Year ECE, SDMCET. E-mail: babru.chavan@gmail.com

Vyas R Murnal, Assistant Professor, Dept of ECE, SDMCET. E-mail: vyasmurnal@gmail.com

DOI: 10.9756/BIJRCE.8196 are switched on in the evening before the sun sets and then switched off the next day morning after there is sufficient light on the roads. However, the switching and transition is not accurate with respect to time as it is manually done at the electric power station units. In addition, there have been evidences of power wastage due to sheer negligence of concerned authority by not switching off the lights even in the day time. This paper gives a better solution for overcoming electrical power wastage and thereby eliminates manual intervention. Luminance is a measure of the perceived power of light per unit area. It is a measure of light intensity that is perceived by the human eye. In this paper, we have used Light Dependent Resistor (LDR) as a sensor to indicate the intensity of light in terms of change in resistance, using which we can get the corresponding lux value of the light. One Lux is equal to one lumen per square metre. The microcontroller Arduino Uno AT328 is used to control the street light system depending upon luminance. An electromagnetic relay is used as output actuator in order to isolate the low power microcontroller from high power electrical systems. Further, a simple analysis of developing a temperature monitoring system is also mentioned.

\section{LITERATURE SURVEY}

There have been many papers on energy management techniques that attempt to reduce the light energy wastage. Paper [1] has proposed a concept on Automatic Street Light Control System using Microcontroller PIC16F877A as a prototype. Paper [2] discusses on the essential implementation aspects of energy conservation with respect to solar energy. The Street lights are also controlled through a specially designed Graphical User Interface (GUI) in the PC. The Zigbee technology can be used for the street lights monitoring and controlling at the PC end.

\section{PROPOSED BLOCK DIAGRAM}

The proposed block diagram shown in Fig.1.explains the general concept of the work undergone.

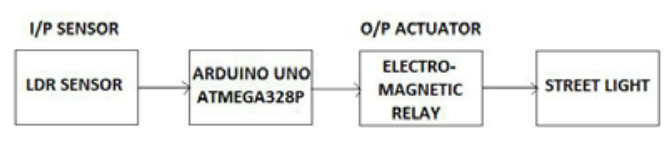

Figure 1: Block Diagram of Automatic Street Light Controller System 
A photo-resistor or light resistor (LDR) or photocell is a device whose resistance decreases with increasing incident light intensity. These devices are found in many consumer appliances such as camera light meters, street lights, clock radios, alarm devices, night lights solar street lamps, etc. Resistance varies linearly with light intensity, which can be used to predict the light ambience. The LDR is connected as one of the resistances of the Wheatstone bridge. Input Voltage (Vdc) is connected across 2 junctions and the voltage at the other two junctions is fed to the non-inverting terminals of two op-amps. The op-amps are in Voltage follower configuration hence the voltage at the non-inverting terminal results into the output of the respective op-amps. These outputs are fed to the third op-amp which is acting as a differential amplifier. Hence the difference in the voltage at the two terminals of the opamp is obtained as output. Hence the output of the circuit is the difference in the voltage at the two junctions of the Wheatstone bridge [3]. When the value of the resistance of the LDR is same as the other resistances of the Wheatstone bridge, the bridge is in balanced condition and the potential difference between the two junctions is 0 and the output voltage is 0 . As the resistance of the LDR changes depending on the intensity of light falling on it, the bridge becomes unbalanced and hence a potential difference develops between the junction and we obtain an output voltage depending on the resistance change. Thus With the voltage obtained, the change in resistance of the LDR can be obtained and with that the intensity of light falling on the LDR can be obtained.

\section{ARDUINO UNO BOARD}

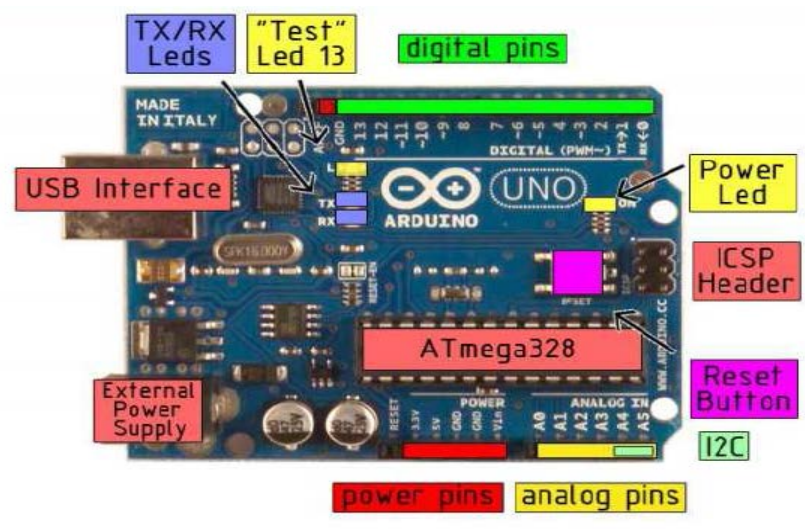

Figure 2: Arduino UNO[4]

The Fig.2 shows the details of an Arduino UNO board. It is open source hardware and can be programmed according to the project requirements. It can be reused again and again with different programs and has a beautifully crafted and very simple coding language. The heart of this board is ATMEGA328P microcontroller chip[4]. It is a 28 pin IC with ceramic resonator of $16-\mathrm{Mhz}$ and $32 \mathrm{~Kb}$ of flash memory for storage. The board has 14 digital input/output pins (of which 6 can be used as PWM outputs), 6 analog inputs, a USB connection, a power jack, an ICSP header, and a reset button. It has a operating voltage of $5 \mathrm{~V}$. Arduino board can be connected to a computer with a USB cable or can be powered it with a AC-to-DC adapter or battery to power the board [5]. It is highly flexible.
A relay is an electrically operated switch. Many relays use an electromagnet to mechanically operate a switch, but other operating principles are also used, such as solid-state relays. Relays are used where it is necessary to control a circuit by a low-power signal (with complete electrical isolation between control and controlled circuits), or where several circuits must be controlled by one signal. We are using relay in our implementation phase, since we are controlling the high power street light using small signal (5V) by the Microcontroller.

The block diagram of the temperature monitoring system using thermistor is mentioned in Fig 3. A NTC thermistor is temperature dependent resistor whose resistance varies in accordance with the temperature. It is low cost and almost maintenance free device yet much reliable. It is connected to the Uno board .Based on its input signal the Uno gives the appropriate output signals.

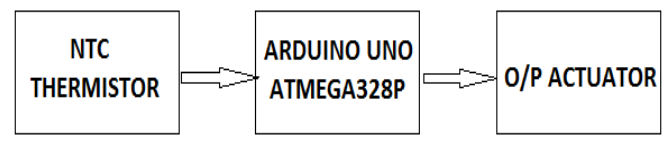

Figure 3: Block Diagram of Temperature Monitoring System using Thermistor

The actuator is a device which acts upon when an input is given to it. Some of the actuators are: Relay, Solenoid, Motor driver, Servo motor, DC motor etc. The Uno gives the signal (either high or low) to the actuator (selection of actuator depends on the application). The actuator receives the signal and acts according to it.

\section{EXPERIMENTAL RESULTS \& DISCUSSIONS}

\section{A. Measurement of Light Intensity}

We have implemented the model on a prototype board to demonstrate its working. We tested the illumination of the light in the open area and the corresponding lux values were calculated. As an open surrounding area we choose a terrace for noting down the readings. Graphs were plotted for the corresponding readings for better understanding and interpretations.

\section{Circuit Diagram}

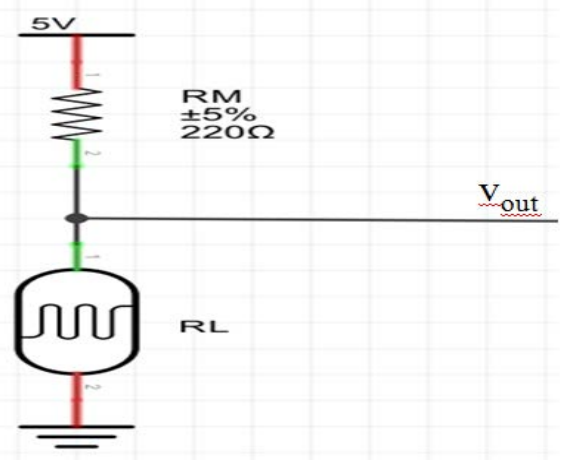

Figure 4: Sensor Circuit

$$
\begin{gathered}
\text { Equations:RL = 500/lux-----(1) } \\
\mathrm{V}_{\text {out }}=5 *(\mathrm{RM} / \mathrm{RL}+220)-----(2) \\
\operatorname{lux}=((2500 / \text { Vout })-500) / 220)-----(3)
\end{gathered}
$$


The resistance of the Light Dependent Resistor (LDR) varies according to the amount of light that falls on it. The relationship between the resistance $\mathrm{R}_{\mathrm{L}}$ and light intensity, Lux for a typical LDR is shown in the equation 1.

Table 1: Experimental Results Showing Variation Lux for Various Timings

\begin{tabular}{|c|c|c|c|c|c|}
\hline Sho & Time & LDR resistance in ohm & o/p voltage in Volts & Arduino & Lux \\
\hline 1 & $5.00 \mathrm{~mm}$ & 355000 & 4.39 & 909 & 0.69 \\
\hline 2 & $6.00 \mathrm{~mm}$ & 404000 & 4.3 & 883 & 0.81 \\
\hline 4 & $7.00 \mathrm{~mm}$ & 850 & 0.08 & 16 & 307.50 \\
\hline 5 & $8.00 \mathrm{~mm}$ & 360 & 0.03 & 4 & 828.33 \\
\hline 6 & $9.00 \mathrm{~mm}$ & 275 & 0.02 & 0 & 1245.00 \\
\hline 1 & $10.00 \mathrm{am}$ & 191 & 0.0131 & 0 & 1819.82 \\
\hline 8 & $11.00 \mathrm{am}$ & 185 & 0.0126 & 0 & 1979.13 \\
\hline 9 & $12.00 \mathrm{pm}$ & 186 & 0.0126 & 0 & 1979.13 \\
\hline 10 & $1.00 \mathrm{pm}$ & 186 & 0.012 & 0 & 2078.33 \\
\hline 11 & $2.00 \mathrm{pm}$ & 190 & 0.012 & 2 & 2078.33 \\
\hline 12 & $3.00 \mathrm{pm}$ & 205 & 0.0126 & 3 & 1979.13 \\
\hline 13 & $4.00 \mathrm{pm}$ & 315 & 0.028 & 3 & 887.86 \\
\hline 14 & $5.00 \mathrm{pm}$ & 760 & 0.073 & 3 & 1081.96 \\
\hline 15 & $6.00 \mathrm{pm}$ & 406 & 0.042 & 5 & 590.24 \\
\hline 16 & $7.00 \mathrm{pm}$ & 76000 & 2.72 & 400 & 4.19 \\
\hline 17 & $8.00 \mathrm{pm}$ & 1020000 & 4.48 & 969 & 0.58 \\
\hline
\end{tabular}

If the LDR is connected to $5 \mathrm{~V}$ through a $220 \Omega$ resistor, using the voltage divider rule, then the resulting output voltage of the LDR is shown as per the equation 2. However, for simplicity we have used a $100 \Omega$ resistor and tabulated the readings. Substituting $R_{L}$ from equation 1 into equation 2 , we obtain the light intensity as in the equation 3 . Table.1. shows the time and corresponding readings for a normal day.

\section{Results Obtained}

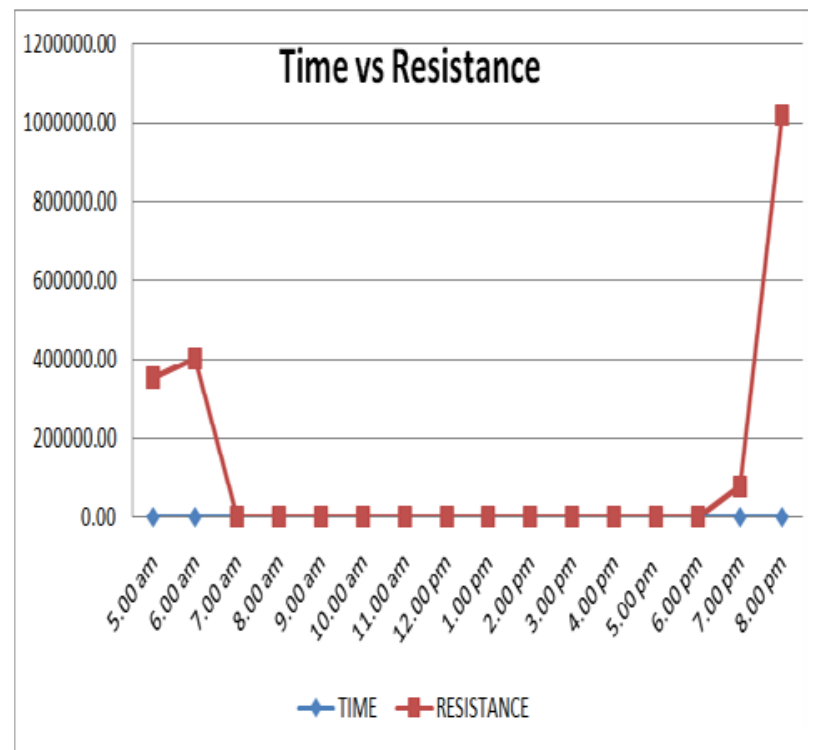

Figure 5: Graph for Time Vs Resistance

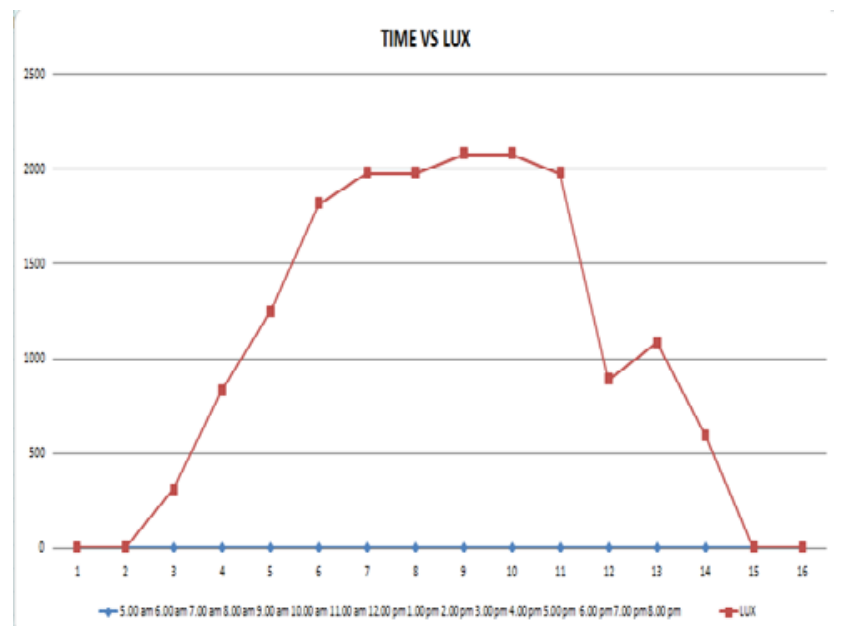

Figure 6: Graph for Time Vs lux

B. Temperature Monitoring

\section{Circuit Diagram}

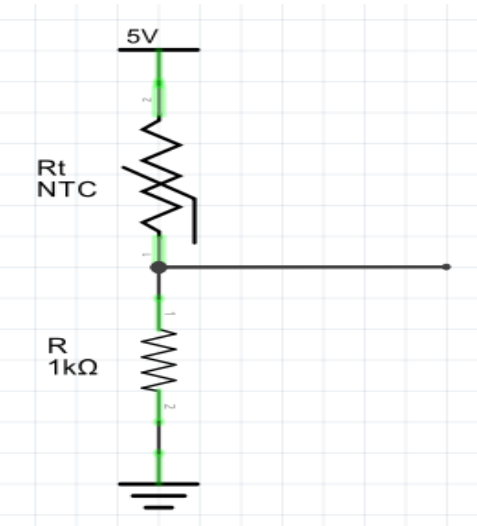

Figure 7: I/P Sensor Circuit

2. Steinhart-Hart Equation

(For temp range $-55^{\circ} \mathrm{C}$ to $150^{\circ} \mathrm{C}$ )

$$
1 / \mathrm{T}=\mathrm{A}+\mathrm{B}(\ln \mathrm{R})+\mathrm{C}(\ln \mathrm{R})^{3}
$$

Where $\mathrm{T}=$ temperature in Kelvin

A, B, C = Coefficients

$\mathrm{R}=$ resistance of thermistor

Co-efficients obtained for the thermistor.

$A=0.001125161025848$

$\mathrm{B}=0.000234721098632$

$\mathrm{C}=0.000000085877049$

Vout $=\mathrm{Rx} 5 /(\mathrm{Rt}+\mathrm{R})$

The Rt is a thermistor whose resistance changes in accordance with the temperature. It is been connected to the $5 \mathrm{v}$ power supply. A $1 \mathrm{k} \Omega$ resistor is connected and both of them are arranged in the voltage divider style. The input to the analog pin of the Uno board is connected across the Rt (Fig 7). The voltage can be determined using eqn. (5). The temperature is varied and the resistance is measured along with corresponding Uno serial monitor value. The corresponding temperature for each obtained resistance is calculated using eqn (4). The readings are mentioned in Table 2 
Table 2: Temperature vs Corresponding Changes in the Resistance

\begin{tabular}{|c|c|c|c|c|}
\hline SL.N0 & $\begin{array}{c}\text { ARDUIN0 } \\
\text { VALCE }\end{array}$ & RESISTANCE(8) & TEMPERATURE (C) & Vg, drop across Rt(V) \\
\hline 1 & 22 & 10000 & 25 & 4.54 \\
\hline 2 & 126 & 7300 & 32.32 & 4.45 \\
\hline 3 & 200 & 4510 & 44.18 & 4 \\
\hline 4 & 300 & 2400 & 61 & 3.53 \\
\hline 5 & 400 & 1600 & 70.7 & 3 \\
\hline 6 & 500 & 1060 & 85.36 & 2.6 \\
\hline 7 & 600 & 750 & 96.37 & 2.05 \\
\hline 8 & 700 & 470 & 113.04 & 1.58 \\
\hline 9 & 800 & 280 & 132.83 & 1.11 \\
\hline 10 & 900 & 150 & 159.36 & 0.61 \\
\hline 11 & 1000 & 20 & 273 & 0.1 \\
\hline
\end{tabular}

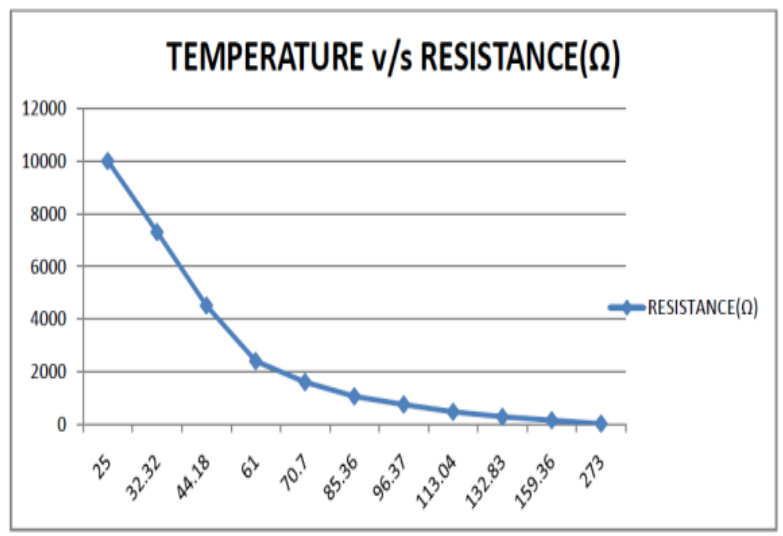

Figure 8: Graph of Temperature vs Resistance

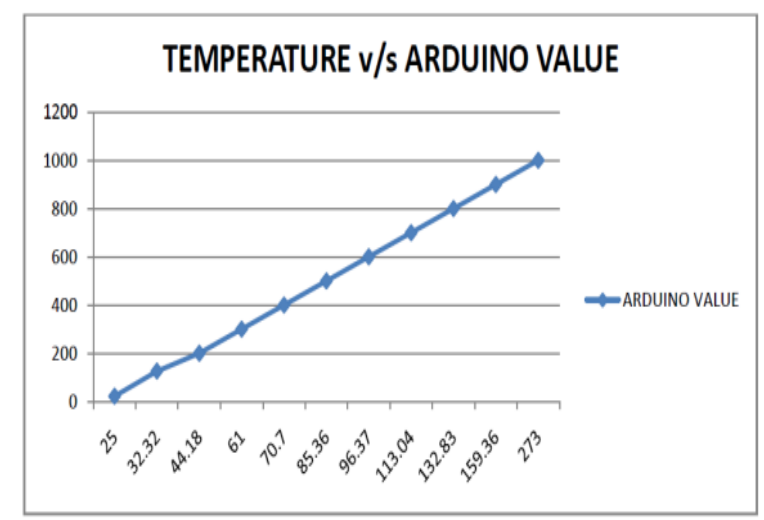

Figure 9: Graph of Temperature vs Arduino Value

\section{CONCLUSION}

From the above analysis and experimental observations and results we are able to infer that as the luminance increases on the surface of the LDR, the resistance of the LDR decreases and with the output voltage obtained from the signal conditioning circuit, we can calculate the luminance that is falling on the LDR. With this, we can prepare a datasheet stating the voltage output for the corresponding light luminance falling on its surface. The variation of luminance on the surface of the LDR is achieved by varying the distance of the light source from LDR and the obtained data shows that the variation follows the inverse square law. The data obtained above can be used to control the street light automatically which ensures power conservation. The paper also provides some insight about temperature monitoring system.

\section{ACKNOWLEDGEMENT}

The authors would like to thank SDMCET, Dharwad for providing essential resources and platform during the course of this experimental work.

\section{REFERENCES}

[1] M. Saad, A. Farij, A. Salah and A. Abdaljalil, "Automatic street light control system using microcontroller", 1st International Conference on Machine Design and Automation, Pp. 92-96, 2013.

[2] B.K. Subramanyam, K.B. Reddy and P.A.K. Reddy, "Design and development of intelligent wireless street light control and monitoring system along with GUI”, International Journal of Engineering Research and Applications (IJERA), Vol. 3, Pp.2115-2119, 2013.

[3] Sameer Pratap Singh and P. Sathya, "Measurement of the illuminance using a Signal Conditioning Circuit", International Journal of Engineering Sciences \& Research Technology, Vol. 3, No. 5, Pp. 574578, 2014.

[4] A.D’Ausilio, “Arduino: A low-cost multipurpose lab equipment”, Behavior research methods, Vol. 44, No.2, Pp. 305-313, 2012.

[5] M. Margolis, "Make an Arduino-controlled robot", O'Reilly Media, Inc.”, 2012.

[6] B. Baker, "Thermistors in Single Supply Temperature Sensing Circuits", AN685, Microchip Technology Inc., 1998.

[7] K.R. Jeyashankar, M. Mahalley and B. Amrutur, "A Time-based Low Voltage Body Temperature Monitoring Unit”, In 2014 27th International Conference on VLSI Design and 2014 13th International Conference on Embedded Systems, Pp. 522-527, 2014.

[8] A.D'Ausilio, “Arduino: A low-cost multipurpose lab equipment”, Behavior research methods, Vol.44, No.2, Pp.305-313, 2012.

[9] M. Margolis, "Make an Arduino-controlled robot”, O'Reilly Media, Inc., 2012. 